\title{
Breeding seabirds increase foraging range in response to an extreme marine heatwave
}

\author{
Orla E. Osborne ${ }^{1, *}$, Patrick D. O'Hara ${ }^{2}$, Shannon Whelan ${ }^{3}$, Paul Zandbergen ${ }^{1}$, \\ Scott A. Hatch ${ }^{4}$, Kyle H. Elliott ${ }^{3}$ \\ ${ }^{1}$ Department of Geography, Vancouver Island University, Fifth Street, Nanaimo, BC V9R 5S5, Canada \\ ${ }^{2}$ Canadian Wildlife Service, Environment and Climate Change Canada, Institute of Ocean Sciences, W. Saanich Rd., Sidney, \\ BC V8L 4B2, Canada \\ ${ }^{3}$ Department of Natural Resource Sciences, McGill University, Ste Anne-de-Bellevue, QC H9X 3V9, Canada \\ ${ }^{4}$ Institute for Seabird Research and Conservation, Anchorage, AK 95516, USA
}

\begin{abstract}
Marine heatwaves are increasing in frequency and can disrupt marine ecosystems non-linearly. In this study, we examined the effect of the North Pacific warming event of 2014, the largest long-term sea surface anomaly on record, on black-legged kittiwake Rissa tridactyla foraging trips before, during, and after the event. We assessed foraging trip characteristics (trip distance and duration), the dispersal of foraging locations, and the persistence of foraging areas within and among years. Foraging trip characteristics, foraging area size, and location varied from year to year. Kittiwake foraging was more dispersed, direct, and farther from the colony in years immediately after and during the warming event. A third of the foraging area used pre-heatwave (2012) was important in subsequent years, which indicates that this area was, and may still be, a perennial foraging hot spot. During the chick-rearing stage, black-legged kittiwakes increased their speed and reduced the proportion of resting compared to the incubation stage. We conclude that marine heatwaves may have a strong impact on seabird foraging, extending foraging ranges, and that those impacts may be nonlinear with a strong lag.
\end{abstract}

KEY WORDS: Seabird · Black-legged kittiwake $\cdot$ Rissa tridactyla $\cdot$ Foraging behaviour · Prey availability $\cdot$ Foraging area

\section{INTRODUCTION}

Marine heatwaves (MHWs) are increasing in intensity and are predicted to become 40 times more common by the middle of the century (Frölicher et al. 2018, Oliver et al. 2019). The northeastern Pacific MHW was first detected in October of 2013, and quickly reached an unprecedented magnitude and duration-peaking in, and lasting throughout, 2016 (Bond et al. 2015, Peterson et al. 2015, Walsh et al. 2018, Holbrook et al. 2019). By January 2014, peak temperatures were recorded in the middle of the northeastern Pacific $\left(42^{\circ} \mathrm{N}, 148^{\circ} \mathrm{W}\right)$ and were about

${ }^{*}$ Corresponding author: orla87@stumail.viu.ca $3^{\circ} \mathrm{C}$ higher than, or 4.5 standard deviations from, the long-term mean (since at least 1982 and possibly 1900) (Freeland \& Whitney 2014, Bond et al. 2015). Similar temperature increases, of $3-4^{\circ} \mathrm{C}$, were seen throughout the Gulf of Alaska (Campbell 2018). The warming effect reached a depth of $100 \mathrm{~m}$, and within a few months it extended into the coastal zone (Bond et al. 2015). By early 2015, the warm water anomaly had extended along the Canadian and US Pacific coasts, south to Baja California, Mexico (Bond et al. 2015, Cavole et al. 2016). This was the largest MHW ever recorded and caused numerous disruptions and alterations to marine and coastal ecosystems (Cavole

() The authors 2020. Open Access under Creative Commons by Attribution Licence. Use, distribution and reproduction are unrestricted. Authors and original publication must be credited. 
et al. 2016, Di Lorenzo \& Mantua 2016, Walsh et al. 2018, Piatt et al. 2020). Disturbances included low primary productivity, transition to warm water zooplankton community assemblages, and harmful algal blooms (Peterson et al. 2015, Whitney 2015, Cavole et al. 2016, McCabe et al. 2016). The MHW was linked to several unusual or mass mortality events, including sea stars, seabirds, whales, and otariids (Savage 2017 , Gibble et al. 2018, Jones et al. 2018, Miner et al. 2018, Harvell et al. 2019, NOAA 2020). Furthermore, the number of poleward range expansions in numerous taxa was unprecedented, including molluscs, crustaceans, cnidarians, echinoderms, ctenophores, tunicates, fish, seabirds, marine mammals, and algae (Peterson et al. 2015, Cavole et al. 2016, Sanford et al. 2019).

Large basin-scale indices such as the Pacific Decadal Oscillation (PDO) are often used to link ocean processes with impacts on marine species/ communities (Ascani et al. 2016, Champagnon et al. 2018, Yang et al. 2019). The PDO index is a measure based on the inter-decadal sea surface temperature (SST) anomalies of the North Pacific (Mantua et al. 1997). The index reflects the difference between the observed SST anomalies and the monthly mean of the global average SST anomaly. The PDO index is either positive (warm phase) or negative (cold phase), and these phases can persist for decades with occasional abrupt reversals (Mantua \& Hare 2002). PDO values correlate strongly, and negatively, with the proportion of the main prey item (capelin Mallotus villosus) in the diet of black-legged kittiwakes Rissa tridacytla (hereafter 'kittiwakes') on Middleton Island, in the Gulf of Alaska (Hatch 2013).

Kittiwakes are very sensitive indicators of food availability (Hatch 2013). The preference of capelin for cool waters links ocean temperature to kittiwake breeding success, as high temperatures reduce capelin availability to foraging seabirds during breeding (Hatch 2013). Thus, the northeastern Pacific MHW likely affected the foraging behaviour of kittiwakes on Middleton Island due to a presumed reduction of capelin.

The responses of kittiwakes to poor food availability include extending their range to find more predictable and profitable prey patches, rather than putting more effort and time into unprofitable prey patches closer to breeding colonies (Suryan et al. 2000, Chivers et al. 2012, Paredes et al. 2014, Christensen-Dalsgaard et al. 2018). However, the constraints of chick-rearing may complicate this relationship, as some seabird species use bet-hedging foraging strategies to balance the need for self-feeding and chick-provisioning (Weimerskirch 1998, Ydenberg \& Davies 2010).
In this study, we examined how space use in breeding kittiwakes varies within and across years before (2012-2013), during (2014-2016), and after (20172018) an extreme MHW (Holbrook et al. 2019). Using GPS tracking data for foraging kittiwakes over 6 years (excluding 2014, for which we have no data), during the incubation and chick-rearing stages of the breeding season, we assessed foraging trip characteristics (trip distance and duration), the dispersal of foraging locations, and the persistence of foraging areas within and among years. We predicted that (1) kittiwake foraging trip characteristics (trip distance and duration) would increase in response to the MHW as birds searched more patches to find sufficient prey; (2) the MHW would increase the distribution of foraging locations and foraging area as patches became more dispersed; (3) local SST and regional PDO would show an inverse relationship to kittiwake productivity during the MHW, because increased foraging trip duration would lead to lower feeding rates; (4) kittiwakes would fly faster, spend more total time commuting, but travel less far, during chick-rearing when they were attempting to maximize feeding rates to the chicks; and (5) lag effects of the MHW would would be markedly different between the incubation and chick-rearing stages as individuals were under stronger demands to maintain chick growth despite low food availability compared to pre-MHW years.

\section{MATERIALS AND METHODS}

\subsection{Study area and data collection}

We collected foraging data at the black-legged kittiwake colony on Middleton Island, Alaska, USA $\left(59.438^{\circ} \mathrm{N}, 146.326^{\circ} \mathrm{W}\right)$. Three types of GPS loggers were used: CATTRAQ GPS (Mr. Lee Technologies; 15 g), i-gotU GPS (Mobile Action Technology; 15 g), and AxyTrek (Technosmart; $12 \mathrm{~g}$ ). The GPS loggers were secured to the birds using zip-ties and TESA marine adhesive tape around the lower back (20122015) or tail (2016-2018) feathers to ensure unimpeded flight. The mass of the loggers varied between 2 and $5 \%$ of body mass. In our initial years (2012 and 2013) we used a 30 s GPS sampling interval. As those measurements demonstrated that even a $300 \mathrm{~s}$ sampling interval had little impact on most measurements of flight speed (Elliott et al. 2014), we used lower sampling intervals in later years to increase battery life. In all years, birds were tagged during the chick-rearing period from late June and July. In 2013 
and 2017, incubating birds were also sampled in late May and June. For interannual comparisons, the chickrearing stage was used because only chick-rearing birds were sampled in 2015 and 2016. Devices were retrieved approximately $24 \mathrm{~h}$ after deployment when possible; within this time, the number of foraging trips logged per individual bird ranged between 1 and 9 (Table 1). Following the findings of Soanes et al. (2013), all trips were included in the analysis to retain important spatial information. Each bird was weighed before and after each deployment to determine whether weight loss occurred due to device deployment. As tagged birds $(\mathrm{n}=98)$ had no greater mass loss than untagged individuals $(n=45)$ ( $t$-test p > 0.2; see also Chivers et al. 2016), we concluded that our devices did not have a large impact on body mass change.

\subsection{Data processing}

GPS data for 2012 was down-sampled to an interval of $30 \mathrm{~s}$ to eliminate bias in the analyses from tracks with lower sampling intervals. Improbable locations were eliminated using a maximum speed threshold of $100 \mathrm{~km} \mathrm{~h}^{-1}$, and that were not sequential with other high speeds. We classified foraging locations into 3 possible at-sea movement behaviours (foraging, resting, and transiting) using a residency
Table 1. Trips made by black-legged kittiwakes, logged during the chick-rearing stage by year

\begin{tabular}{|ccccc|}
\hline Year & $\begin{array}{c}\text { Total } \\
\text { no. of } \\
\text { trips }\end{array}$ & $\begin{array}{c}\text { No. of } \\
\text { ind. }\end{array}$ & $\begin{array}{c}\text { Trips per } \\
\text { bird } \\
\text { (min.-max.) }\end{array}$ & $\begin{array}{c}\text { Average } \\
\text { trips } \\
\text { per bird }\end{array}$ \\
\hline 2012 & 34 & 22 & $1-4$ & 1.55 \\
2013 & 191 & 39 & $2-8$ & 4.90 \\
2015 & 27 & 18 & $1-3$ & 1.50 \\
2016 & 43 & 12 & $1-8$ & 3.58 \\
2017 & 224 & 60 & $1-9$ & 3.73 \\
2018 & 178 & 37 & $1-8$ & 4.81 \\
\hline
\end{tabular}

in space and time (RST) model (Torres et al. 2017). This movement model was chosen using a matrix to compare the many available options. The requirements of the movement model were that it meet the demands of the study data and objectives, identify foraging, resting, and transiting behaviours, and that its methods were validated and used in case studies similar to our study (Torres et al. 2017, Courbin et al. 2018, Sullivan \& Torres 2018, Adams et al. 2019, Kroeger et al. 2019). For more information on the methods used to choose this movement model, see Osborne (2018). We also calculated total distance, duration, maximum distance, and directness. Directness was calculated using the maximum distance divided by the total distance travelled, then multiplied by 100 for data visualization purposes. ArcGIS

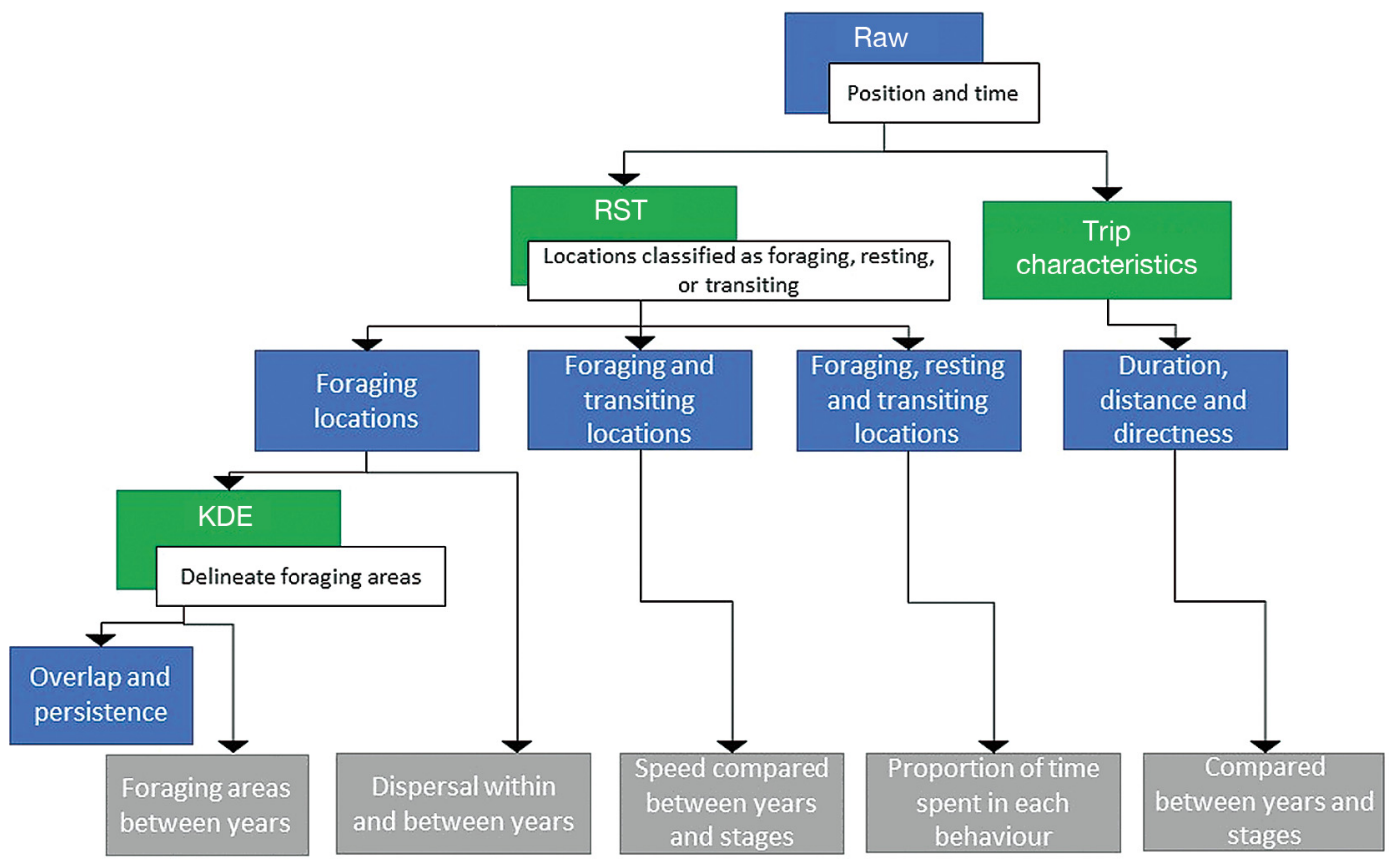

Fig. 1. Methodology used in this study, showing data processing (green boxes), products (blue boxes), and analyses (grey boxes). White boxes describe overlapping blue and green boxes. RST: residency in space and time; KDE: kernel density estimate 
10.5.1 was used to plot the coordinates from the GPS data and create the maps (coordinate system and projection: WGS 1984 and NAD 83, Alaska Albers Conical Equal Area). A flow chart of the methods used in this study is depicted in Fig. 1.

\subsection{Interannual variability}

\subsubsection{Foraging area}

Typically, kernel density estimates (KDEs) are used to delineate seabird species home ranges and foraging areas from entire foraging tracks, using the $95^{\text {th }}$ and $50^{\text {th }}$ percentiles as breaklines to bound these areas, respectively (Pinaud \& Weimerskirch 2007, Yorio et al. 2010, Montevecchi et al. 2012, Pollet et al. 2014). The $50^{\text {th }}$ percentile contour is used to distinguish foraging areas from the entire home range. In our study, we first used the RST movement model to classify foraging locations, then a KDE using only foraging locations to delineate foraging areas. Other studies using a similar approach of first filtering track locations for specific behaviours and then delineating areas using a KDE include Dean et al. (2013), Harwood et al. (2017), and Paredes et al. (2014). Using a KDE, foraging areas were delineated for each yearly foraging dataset. KDEs are highly sensitive to bandwidth selection (i.e. radius of estimator) and defining a bandwidth using objective criteria can be a problem (Zambom \& Dias 2013). We used a novel approach to estimate the KDE bandwidth: foraging locations were used to calculate the average foraging patch size, and the dimensions of patch sizes were used to inform bandwidth choice.

To help define foraging patches, we identified foraging bouts, because foraging trips often involve more than one foraging bout. Foraging locations were grouped into foraging bouts (a proxy for foraging patch size) using a time threshold between foraging locations. The R package 'diveMove' (Luque 2020) was used to determine the time threshold beyond which a foraging location marks a separate foraging bout (the bout-ending criterion, BEC). This log frequency method is based on the work by Sibly et al. (1990) and Langton et al. (1995). Specifically, the BEC was determined by fitting an exponential function to determine a BEC time as implemented in other studies (Luque et al. 2008, Gutowsky et al. 2014, Rekdahl et al. 2015). Time intervals from data gaps were omitted from the BEC calculation because they artificially increased the BEC. Once the BEC was determined, we applied it to trips filtered for for- aging locations, which grouped the locations into bouts (see Appendix A6 in Osborne 2018).

Each foraging bout was then contained in a convex hull polygon to represent a foraging patch. The longer axis (the equivalent of foraging patch diameter, using the $90^{\text {th }}$ percentile of patch length) was divided by 2 (to equal the radius) and used as the bandwidth of the KDE. We used the long axis of the polygon because KDEs have been found to underestimate areas used by animals (Fleming et al. 2015). A range of bandwidths was then determined using the foraging bout procedure described above, and from this, the mid-range value $(7.31 \mathrm{~km})$ was used as a single bandwidth value and applied to all KDEs for all years. The same bandwidth was used for each year to mitigate any possible bias towards a larger bandwidth for years with a larger sampling interval.

To account for biases in the KDE relating to an unequal contribution by individual birds, KDE was calculated per individual rather than per trip. We normalized KDE by converting cell values into proportions of the whole KDE raster. All KDE rasters (for a given year) were then added together and divided by the number of rasters. These 3 steps made the contribution of each bird equal and avoided pseudoreplication. All KDE cells with a probability of 0 were omitted, and the KDEs were then bounded using the $80^{\text {th }}$ percentile as a break-line. In the interest of comparing yearly foraging areas quantitatively, a single bounding contour was used. The $80^{\text {th }}$ percentile was chosen in 2 steps. The first step was to determine a minimum break-line for each yearly KDE that encompassed all foraging locations (using every tenth quantile as an option). In the second step, we found the average of those break-lines (the minimum quantile that included all foraging locations). This resulted in a single break-line that was applied to all years. Using the $80^{\text {th }}$ percentile as a break-line offered a balance between illustrating important foraging grounds while not overestimating or underestimating their size. Although the choice of a $95^{\text {th }}$ percentile is more traditional, the $80^{\text {th }}$ percentile has been used in ecological studies, and made the most biological sense for our data (Masello et al. 2010, Kessler et al. 2013, Bauduin et al. 2018, Kirkpatrick et al. 2018).

To determine the foraging area, a total count of cells with probability values greater than 0 was multiplied by the cell dimensions $\left(285.35 \mathrm{~m}^{2}\right)$ of the final stacked KDE for each year. The area was then converted to $\mathrm{km}^{2}$ as a final value. The overlap in area between years was calculated by multiply- 
ing the KDE surfaces for each year within the yearly range to be determined. The persistence of foraging area from previous years was calculated by dividing the area of overlap by the initial year in the range.

\subsubsection{Foraging distribution}

The average directional distribution, strength of directional trend, and spatial dispersal (i.e. spread) of foraging locations for each yearly foraging dataset were determined using a standard deviation ellipse (ArcGIS version 10.5.1). The standard deviation ellipse was calculated using the standard deviation of the $x$-coordinates and $y$-coordinates for foraging locations from the mean centre to define the axes of the ellipse. From this, the interannual variability in foraging direction and dispersal was qualitatively compared. We measured the strength of the directional trend using the ratio of the short to long axis of the dispersal ellipse subtracted from 1.

\subsubsection{Environmental variability}

To assess environmental variability experienced by the kittiwakes, the average SST and PDO index trends were compared to kittiwake productivity over the same period. Daily SST satellite imagery (from Marine Geospatial Ecology tools, version 0.8a69, Roberts et al. 2010) from May to August was averaged into a single image for each year. We cropped the image to the boundary of the cumulative foraging areas and calculated an average pixel value to represent the average temperature experienced by kittiwakes each year. The PDO Index values used in Fig. 4 were downloaded from NOAA (https://www. ncdc.noaa.gov/teleconnections/pdo/).

\subsection{Comparison of foraging during incubation and chick-rearing}

For 2013 and 2017 (pre- and post-heatwave years with data collected during both incubation and chick-rearing), we calculated total trip distance, trip duration, maximum distance, directness, time budgets (resting, foraging, and transiting), and speed for each stage. We calculated time budgets by dividing the number of locations for each behaviour by the total number of trip locations. To assess whether kittiwakes increased their transit and/or foraging speed in the chick-rearing stage, we determined the speed for both behaviours. We calculated the speed between sequential points in a trip using distance between adjacent points divided by the time elapsed between them. We then filtered for the behaviour of interest and found the median speed.

\subsection{Statistical analyses of trip characteristics}

To test for interannual variation in kittiwake foraging behaviour, we used the R package 'glmm ADMB' (Bolker et al. 2012) to generate separate multiple generalized linear mixed models (GLMMs; log link). The error distribution used in the model was the gamma family because it is suitable for non-negative continuous response data that are positively skewed (Anderson et al. 2012). Individual was a random effect and year was a fixed effect. Distance, duration, maximum distance, and directness were the response variables for each of the 4 models. Spearman's rank correlation was used to test whether there was a correlation between trip distance and chick age for pooled years of trips with chick ages between 5 and $25 \mathrm{~d}$.

We used 'multcomp' (Hothorn 2020) for post hoc comparisons, and a Tukey contrast test using the single-step adjusted $\mathrm{p}$-value method to adjust for multiple comparisons. We used the same procedure to examine the effect of stage (a fixed effect) in 2013 and 2017. Foraging and transit speeds were compared between stages using an unpaired MannWhitney $U$-test, because parametric test assumptions of normality were unmet. A cumulative link model, from the $\mathrm{R}$ package 'ordinal' (Christensen 2019), was run using a logistic link function to compare the proportion of trip behaviours (resting, foraging, and transiting) identified in an RST model (Torres et al. 2017) in 2013 and 2017. The 6 behaviour-stage combinations were used as predictors (e.g. restingincubation, foraging-chick-rearing), and the associated behaviour proportion as the response variable. We ran each year separately. To avoid pseudoreplication of individual birds making multiple trips, only the first trip made by an individual was used in the analysis. Post hoc analyses were performed to determine which levels of behaviour and stage differed. For this, a Tukey pairwise comparison test was used, and p-values were adjusted by the false detection-rate method to correct for false discoveries that may occur with multiple comparisons. All statistical analyses were performed using $\mathrm{R}$ version 3.5.0. 


\section{RESULTS}

\subsection{Interannual variability}

Duration (Fig. 2B; $\mathrm{df}=5$, likelihood ratio test [lrt] $=$ 68.48, p < 0.001), maximum distance (Fig. $2 C_{;} d f=5$, lrt $=165.04, p<0.001$ ), and directness (Fig. 2D: $\mathrm{df}=5$, lrt $=126.42, p<0.001)$ all varied among years (Table 2$)$ Total distance was correlated with maximum distance and varied among years ( $\mathrm{df}=5, \mathrm{lrt}=105.82, \mathrm{p}<$ 0.001 ). No trip characteristic was significantly different for the 2015-2016 pair, and all were significantly different between 2013 and each of 2015, 2017, and 2018. Maximum distance and directness were also
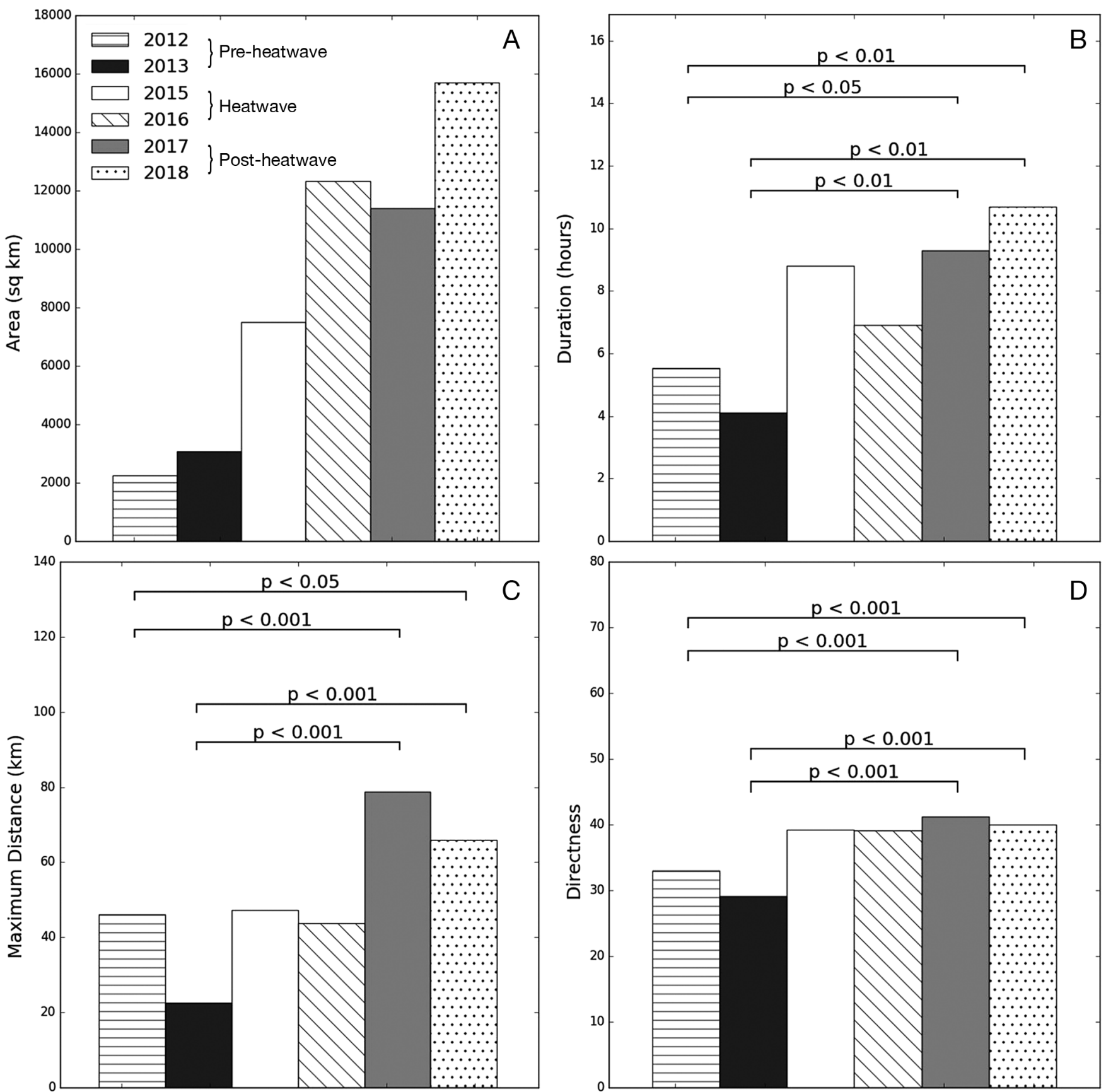

Fig. 2. Trends in (A) foraging area, (B) trip duration, (C) maximum distance of trips and (D) trip directness during the chick-rearing stage of black-legged kittiwake breeding. Sample sizes for trip characteristics were 34 trips in 2012, 192 trips in 2013, 27 trips in 2015, 30 trips in 2016, 188 trips in 2017, and 180 trips in 2018. Brackets indicate significant contrasts between years 
Table 2. Trends in trip characteristics between pre-warming years (2012 and 2013), warming event (2015 and 2016$)$, and post-warming years (2017 and 2018) for black-legged kittiwakes

\begin{tabular}{|c|c|c|c|}
\hline \multirow{2}{*}{$\begin{array}{l}\text { Trip } \\
\text { characteristic }\end{array}$} & \multicolumn{3}{|c|}{ Statistically significant trends from pre-warming through post-warming periods } \\
\hline & Pre-warming (2012 and 2013) & Warming event (2015 and 2016) & Post-warming (2017 and 2018) \\
\hline Distance & $\begin{array}{l}\text { Increase within pre- } \\
\text { warming years }\end{array}$ & & $\begin{array}{l}\text { Increase from pre-warming years; } \\
\text { increase from } 2016 \text { to } 2017\end{array}$ \\
\hline Duration & & & Increase from pre-warming years \\
\hline $\begin{array}{l}\text { Maximum } \\
\text { distance }\end{array}$ & $\begin{array}{l}\text { Increase within pre- } \\
\text { warming years }\end{array}$ & Increase from 2013 to 2015 & $\begin{array}{l}\text { Increase from pre-warming years; } \\
\text { increase from } 2016 \text { to } 2017\end{array}$ \\
\hline Directness & $\begin{array}{l}\text { Increase within pre- } \\
\text { warming years }\end{array}$ & $\begin{array}{l}\text { Increase from pre- } \\
\text { warming years }\end{array}$ & Increase from pre-warming years \\
\hline
\end{tabular}

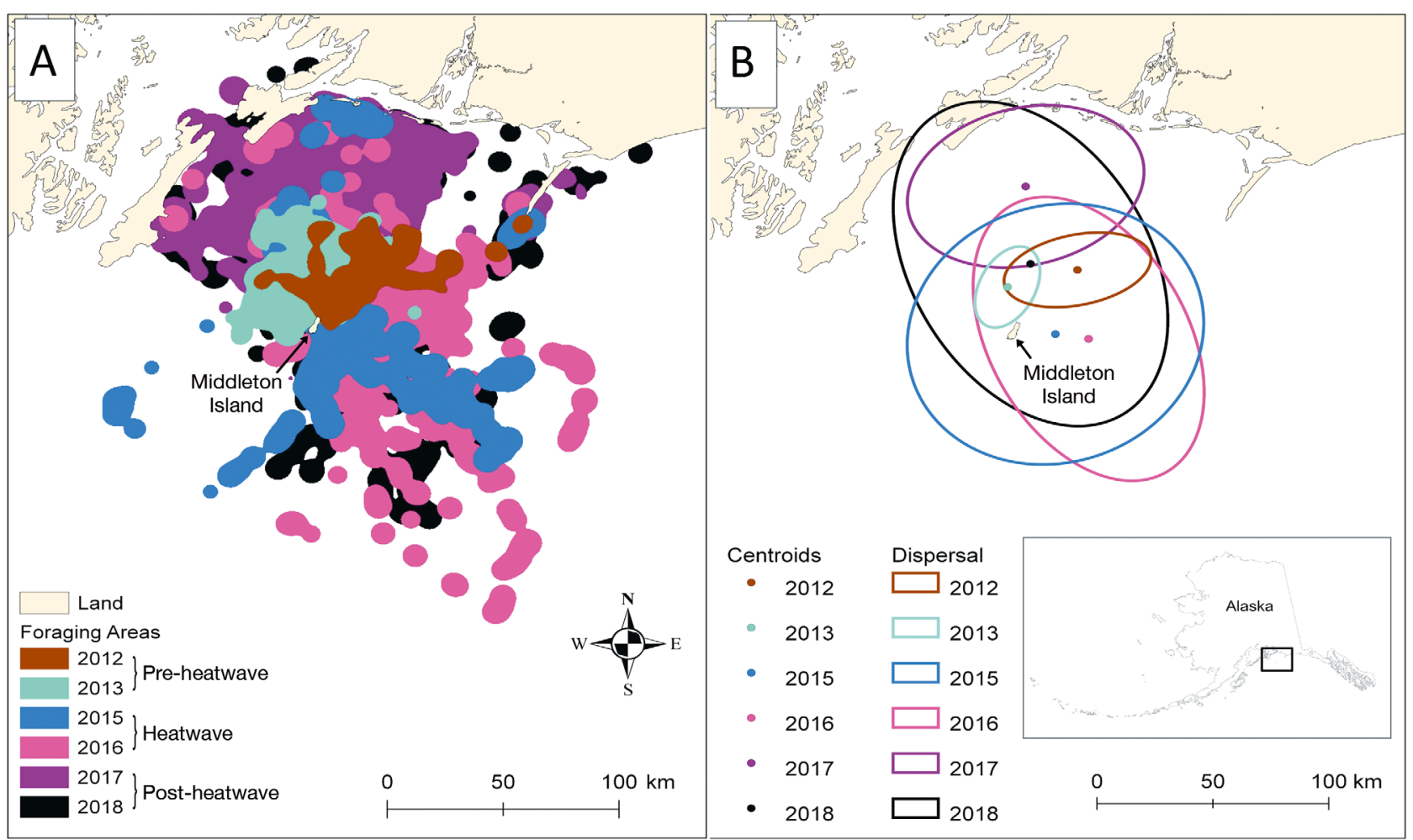

Fig. 3. (A) Kernel density estimations reclassified to calculate area, overlap, and persistence from year to year. The $80^{\text {th }}$ percentile was used as a break-line for delineating areas. (B) Size, orientation, and centroid of the foraging ellipse during each year of the study

significantly different between the 2013 and 2016 pair. All trip characteristics were significantly different for 2012 and each of 2017 and 2018 (except for the 2012-2018 trip distance). There was no correlation between trip distance and chick age for pooled trips $(\mathrm{N}=590)$ from 2012 to $2018(S=34579000, \mathrm{p}=$ 0.81 , rho $=-0.01$ ).

The smallest cumulative foraging area (pooling among individuals) occurred in 2012 followed by
$2013,2015,2017$, and 2016. The largest cumulative foraging area occurred in 2018 (Figs. 2A \& 3). Approximately one-third to over a half of the area used in 2012 was important in subsequent years; 57 to $30 \%$ of the 2012 foraging area was reused from 2013 to 2018, respectively (Table 3). In 2018, there was generally the same proportion of re-use of foraging areas from previous years $-43 \%$ of the $2013,31 \%$ of the 2015 , and $33 \%$ of the 2016 for- 
Table 3. Persistence of foraging areas of black-legged kittiwakes from 2012 through to 2018, as a percentage of the initial year being considered. Overlap of foraging areas in a pair of years was divided by area during the first year to gauge persistence

\begin{tabular}{|lccc|}
\hline From (a) & To (b) & $\begin{array}{c}\text { \% of area used } \\
\text { in year a also } \\
\text { used in year b }\end{array}$ & $\begin{array}{c}\text { Area }\left(\mathrm{km}^{2}\right) \text { used } \\
\text { in year a also } \\
\text { used in year b }\end{array}$ \\
\hline 2012 & 2013 & 57 & \\
2012 & 2015 & 36 & \\
2012 & 2016 & 34 & \\
2012 & 2017 & 34 & \\
2012 & 2018 & 30 & \\
2013 & 2015 & 57 & \\
2013 & 2016 & 46 & \\
2013 & 2017 & 46 & 2306 \\
2013 & 2018 & 43 & 4029 \\
2015 & 2016 & 56 & 8711 \\
2015 & 2017 & 32 & \\
2015 & 2018 & 31 & \\
2016 & 2017 & 39 & \\
2016 & 2018 & 33 & \\
2017 & 2018 & 76 & \\
\hline
\end{tabular}

Table 4. Foraging-area ellipse derived from 1 standard deviation of all foraging locations for a given year, and the strength of the directional trend ( 1 - [short axis/long axis])

\begin{tabular}{|ccc|}
\hline \multirow{2}{*}{ Year } & \multicolumn{2}{c|}{$\begin{array}{c}\text { Dispersal and direction } \\
\end{array}$} \\
& Ellipse area $\left(\mathrm{km}^{2}\right)$ & Strength of directional trend \\
\hline 2012 & 1710 & 0.48 \\
2013 & 794 & 0.41 \\
2015 & 12568 & 0.08 \\
2016 & 9908 & 0.40 \\
2017 & 6152 & 0.28 \\
2018 & 13626 & 0.37 \\
\hline
\end{tabular}

aging areas (Table 3). Although the proportion of re-used foraging areas did not change much from 2012 to 2016, the size of the foraging areas that were re-used did. Each year saw an approximate doubling in the size of the foraging area that was reused up until 2018 (Table 3). The greatest dispersal of foraging locations occurred in 2018, followed by 2015, 2016, and 2017. Dispersal was far less in 2012 and 2013 (Fig. 3B, Table 4). PDO and SST increased from 2012 to 2015 and 2016, respectively, and then fell. This corresponded to a decrease in kittiwake productivity from 2013 to 2016, after which a modest increase occurred (Fig. 4).

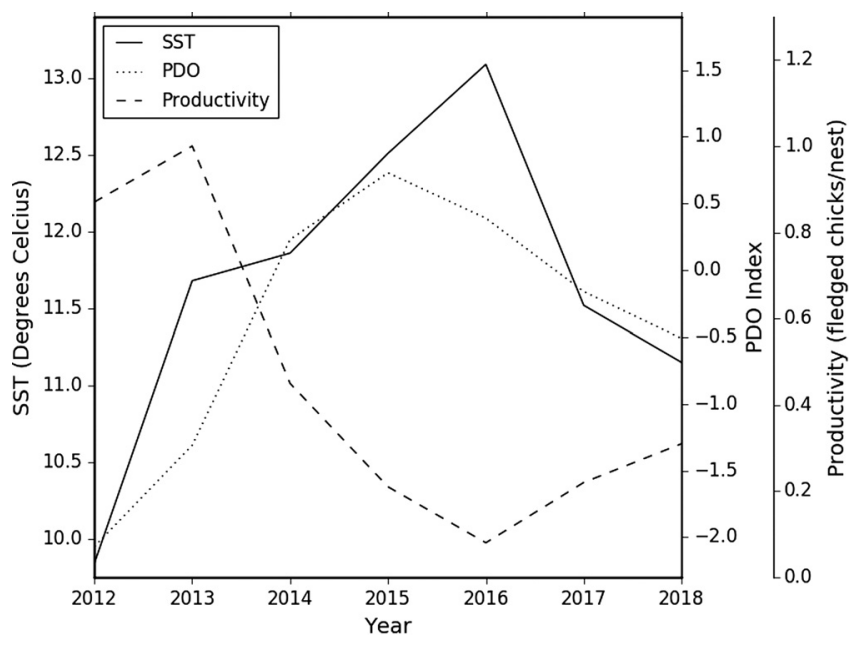

Fig. 4. Average sea surface temperature (SST) within cumulative foraging areas, Pacific Decadal Oscillation (PDO) index, and the productivity (fledged chicks per nest) of blacklegged kittiwakes on Middleton Island

\subsection{Breeding stage}

In 2013, kittiwakes travelled a greater total distance (Fig. 5: lrt $=8.38, \mathrm{p}<0.01$ ), but were less direct (Fig. 5: lrt $=23.62, \mathrm{p}<0.001$ ) during the chick-rearing stage as compared to the incubation stage. No difference was found in duration (Fig. 5 : 1rt $=0.05, p=0.83$ ) or maximum distance (lrt $=0.78, \mathrm{p}=0.38$ ) from the colony (Fig. 5). In 2017, kittiwakes travelled less far in total distance (lrt $=34.7, p<0.001)$, spent less time away from the colony per trip $(l r t=55.31, p<0.001)$, flew shorter maximum distances (lrt $=16, \mathrm{p}<0.01$ ), and were more direct (lrt $=20.28, \mathrm{p}<0.001)$ during the chick-rearing stage (Fig. 5). Kittiwakes increased their foraging speed between incubation and chickrearing stages in $2013(W=15935, \mathrm{p}<0.001)$, but did not significantly increase their transit speed $(W=$ 13094, $\mathrm{p}=0.14$ ) (Fig. 5). They increased their foraging $(W=10674, \mathrm{p}<0.001)$ and transit $(W=11679, \mathrm{p}<$ 0.001) speeds during the chick-rearing stage of 2017 (Fig. 5).

Behaviour varied with stage in 2013 (2013: $\chi^{2}=$ 79.49, df $=5, \mathrm{p}<0.001)$ and 2017 (2017: $\chi^{2}=36.14$, $\mathrm{df}=5, \mathrm{p}<0.001$ ) (Fig. 5). In 2013, chick-rearing kittiwakes decreased time spent resting $\left(p_{\text {adj }}=0.04\right)$ but not the time spent foraging $\left(\mathrm{p}_{\mathrm{adj}}=0.21\right)$ or transiting $\left(p_{\text {adj }}=0.24\right)$ (Fig. 5). In 2017, chick-rearing birds decreased their foraging time $\left(p_{a d j}<0.0001\right)$ and resting time $\left(\mathrm{p}_{\mathrm{adj}}=0.015\right)$ while increasing their time spent transiting $\left(\mathrm{p}_{\mathrm{adj}}=1.054 \times 10^{-07}\right)$ (Fig. 5). Dispersal, direction, and overlap were very similar between stages. 

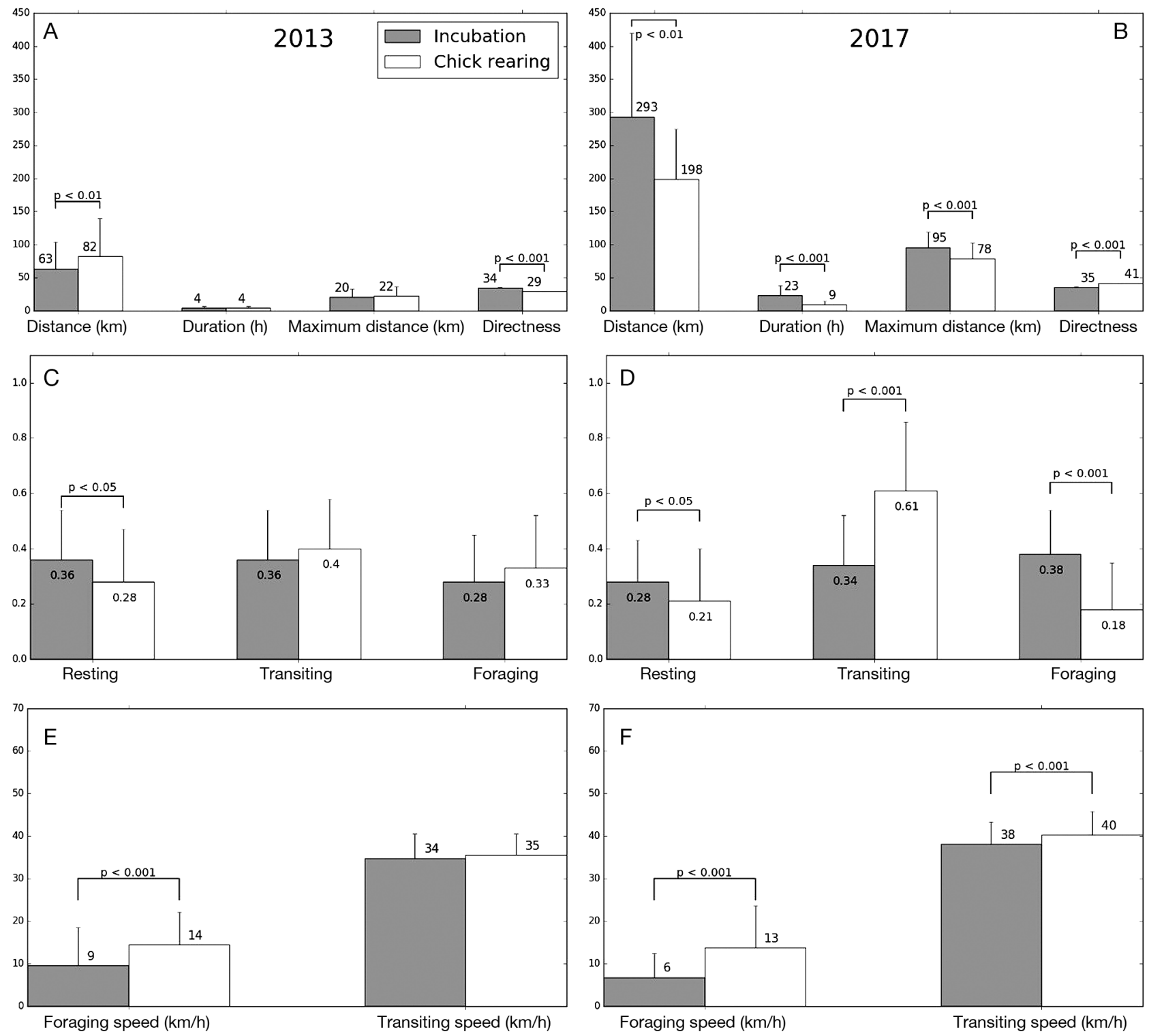

Fig. 5. Comparisons of $(\mathrm{A}, \mathrm{B})$ trip characteristics, $(\mathrm{C}, \mathrm{D})$ trip behaviours, and $(\mathrm{E}, \mathrm{F})$ flight speeds between the incubation and chick-rearing stages of black-legged kittiwakes in $2013(\mathrm{~A}, \mathrm{C}, \mathrm{E})$ and 2017 (B,D,F). Error bars represent SD

\section{DISCUSSION}

\subsection{Interannual variability}

The effect of the MHW was clearly seen around the kittiwake colony on Middleton Island, as the PDO and SST increased during the heatwave. Prior to the heatwave (2012-2013), kittiwake reproductive success was high and the preferred prey (capelin) comprised a high proportion of the birds' diet (Institute for Seabird Research and Conservation 2018). The relationship between capelin abundance and foraging area illustrates the extent to which kittiwake for- aging and capelin dynamics are linked. In years when capelin was abundant (2012 and 2013), kittiwakes foraged in smaller areas compared to years when capelin abundance was low (2014 to 2018) (von Biela et al. 2019). However, in 2018, post-heatwave, the foraging area was much larger than in previous years. Presumably, when capelin is not available, kittiwakes expand their search spatially for profitable foraging areas, whereas when capelin are available close to the colony, kittiwakes feed there.

The effect the MHW had on foraging trip characteristics remained after the heatwave dissipated. As foraging conditions worsened during the MHW, kitti- 
wakes covered more distance (and flew more directly to those farther sites) to find food, spent more time in search of profitable foraging areas, and travelled farther compared to pre-MHW years - as has been observed in other seabirds in response to climatic anomalies (Bost et al. 2015). Yet post-heatwave years also differed significantly from pre-heatwave years in foraging trip characteristics. In fact, post-heatwave foraging availability and kittiwake response were similar to those encountered during the heatwave. Thus, the effect of the heatwave on the local ecosystem continued well after the heatwave itself had dissipated. Despite the kittiwakes' need to forage over a larger area, however, one-third to over half of the foraging area used in 2012 was used in subsequent years. This indicates that although the pre-MHW foraging area was not adequate to meet the entire foraging needs of the colony during and after the MHW, it was still a reliable source of prey from year to year, i.e. there was a need to expand the range, not replace it with another because the former range was insufficient to meet foraging requirements.

\subsection{Breeding stage}

In a good foraging year (2013) total trip distance (but not duration) was greater during chick-rearing than incubation. Kittiwakes spent more time on the water during incubation, presumably digesting food or resting. Maximum distance did not differ significantly between breeding stages. During chick-rearing, more time was spent searching close to the colony to increase chick-feeding rates, leading to a decrease in path directness. In a poor foraging year (2017), when kittiwakes consistently foraged longer and farther away from the colony, regardless of stage, their total distance travelled and trip duration were smaller during chick-rearing. Trip distance and duration likely were constrained by a chick-feeding frequency of twice per day. Conversely, during incubation, birds could seek out better foraging areas with no necessity to be as direct or as fast as possible. Although the average total distance for the chickrearing stage in 2017 was much less than in the incubation stage, chick-rearing distance in 2017 was still more than double that of the incubation and chickrearing stages in 2013. A balance was struck perhaps between finding enough food and maintaining a minimum frequency of chick-feeding necessary during the chick-rearing stage in 2017. This was also facilitated by flying faster and resting less during each trip. Significant overlap of foraging areas dur- ing the chick-rearing and incubation stages in 2013 and 2017 suggest that prey dynamics vary more between years than within years. Although we did not track non-breeding birds, individuals freed from the constraint of central-place foraging due to nest failure may have ranged even farther than incubating birds (Votier et al. 2017).

At the chick-rearing stage, kittiwakes increased their foraging speed in 2013 and foraging and transit speeds in 2017 to maximize their food delivery rate to chicks. Norberg (1981) predicted that the cost of reproduction would lead to an increase in maximum speed during chick-rearing over incubation, which we observed. In both years, birds spent less time resting when they had chicks to feed. In 2013, there was little variation in foraging or transiting between chick-rearing and incubation. In 2017, less time was spent foraging during the chick-rearing stage, which was not expected. More overnight trips to the coast of the Gulf of Alaska were made during the incubation stage, and each trip lasted much longer because greater time was spent near the mainland rather than flying back to the colony. Kittiwakes transited to foraging areas, spent the night near coastal islands and the mainland, then spent the following day foraging before transiting back to the Middleton colony to relieve their mate. This greatly reduced the amount of transiting relative to foraging for a given trip because most of the foraging locations in 2017 were near the coast. This phenomenon also explains the large difference in trip durations and distances despite the high spatial overlap in foraging areas between the 2 stages.

\section{CONCLUSIONS}

Most recent MHWs are likely caused by humaninduced global warming, the progression of which is predicted to extend the duration, increase the frequency, and intensify the magnitude of MHWs throughout the $21^{\text {st }}$ century should global warming hit the projected increase of $1.5-3.5^{\circ} \mathrm{C}$ (Frölicher et al. 2018, Walsh et al. 2018, Oliver et al. 2019). Thus, the future for several vulnerable populations of seabird species and many other marine species looks bleak in light of the devastation to the marine ecosystem caused by the northeastern Pacific MHW (Jones et al. 2018, Miner et al. 2018, Harvell et al. 2019, Piatt et al. 2020).

The response of kittiwakes to the northeastern Pacific MHW of 2014-2016 was an increase in foraging area and trip characteristics as the birds increased 
their search efforts to find adequate prey in an environment where prey patches were more dispersed and less profitable. By comparing kittiwake foraging before, during, and after the MHW of 2014, we have demonstrated, like others, that kittiwakes are capable of flexible foraging strategies, leading to variability in foraging areas and foraging behaviour from year to year (Hamer et al. 1993, Daunt et al. 2002, Paredes et al. 2014, Christensen-Dalsgaard et al. 2018). However, despite the flexible foraging strategy of kittiwakes, kittiwake productivity declined during the MHW, and it could take years before the effects on recruitment and thus population dynamics are realized (von Biela et al. 2019). The apparent lag between the dissipation of the MHW and the response of the kittiwakes suggests a low ecosystem resilience to ocean-climate events of this duration and magnitude in the Gulf of Alaska.

The link between warmer ocean temperatures, local capelin abundance, the MHW, and the response of the kittiwakes at Middleton Island described in this study suggests that as the intervening years between MHW events become warmer on average, the kittiwake population is less likely to encounter the necessary conditions to make a strong recovery.

The effect the MHW had on the kittiwake population was less severe than for other documented seabird populations that suffered mass mortality and colony failure (Jones et al. 2018, 2019, Zador \& Yasumiishi 2018, Piatt et al. 2020). However, with more extreme MHWs predicted, the impacts on kittiwakes will likely be more severe and longer lasting. A destabilization of the marine ecosystem from extreme MHWs could cause unanticipated and irreversible changes, especially if pushed beyond its limit of resilience (Frölicher et al. 2018).

Acknowledgements. We thank L. Chivers, S. Collins, J. Cunningham, K. Lalla, A. Mouillier, and S. Kahane-Rapport for their help with GPS and accelerometer deployments from 2012 to 2018, and numerous others who helped with the collection of supporting data on kittiwakes used in our analysis. R. Orben provided feedback on the output and interpretation of RST modelling. O.E.O. was funded by a Natural Sciences and Engineering Research Council of Canada (NSERC) Alexander Graham Bell scholarship. Funding for GPS-accelerometers was from the Canada Research Chair in Arctic Ecology and the Canadian Foundation for Innovation. In-kind support was provided to P.D.O. by the Canadian Wildlife Service (Environment and Climate Change Canada) and the Institute of Ocean Sciences (Department of Fisheries and Oceans Canada). An earlier version of the manuscript appeared in O.E.O.'s Master of GIS Applications thesis at Vancouver Island University, which greatly benefitted from comments made by committee members M. Govorov and D. Cake. All methods were approved by the Animal Care Committee at McGill University (AUP no. 7599).

\section{LITERATURE CITED}

Adams J, Felis JJ, Czapanskiy MAX, Carle RD, Hodum PJ (2019) Diving behavior of pink-footed shearwaters Ardenna creatopus rearing chicks on Isla Mocha, Chile. Mar Ornithol 47:17-24

Anderson CJ, Verkuilen J, Johnson TR (2012) Applied generalized linear mixed models: continuous and discrete data. https://education.illinois.edu/docs/default-source/ carolyn-anderson/edpsy587/GLM_GLMM_LMM.pdf

Ascani F, Van Houtan KS, Di Lorenzo E, Polovina JJ, Jones TT (2016) Juvenile recruitment in loggerhead sea turtles linked to decadal changes in ocean circulation. Glob Change Biol 22:3529-3538

* Bauduin S, McIntire E, St-Lauren MH, Cumming SG (2018) Compensatory conservation measures for an endangered caribou population under climate change. Sci Rep 8:16438

Bolker B, Skaug H, Magnusson A, Nielsen A (2012) Getting started with the glmmADMB package. http://glmmadmb. r-forge.r-project.org/glmmADMB.pdf

*Bond NA, Cronin MF, Freeland H, Mantua N (2015) Causes and impacts of the 2014 warm anomaly in the NE Pacific. Geophys Res Lett 42:3414-3420

Bost CA, Cotté C, Terray P, Barbraud C and others (2015) Large-scale climatic anomalies affect marine predator foraging behaviour and demography. Nat Commun 6:8220

Campbell RW (2018) Hydrographic trends in Prince William Sound, Alaska, 1960-2016. Deep Sea Res II 147:43-57

Cavole LM, Demko AM, Diner RE, Giddings A and others (2016) Biological impacts of the 2013-2015 warm-water anomaly in the Northeast Pacific: winners, losers, and the future. Oceanography 29:273-285

* Champagnon J, Lebreton JD, Drummond H, Anderson DJ (2018) Pacific Decadal and El Niño oscillations shape survival of a seabird. Ecology 99:1063-1072

* Chivers LS, Lundy MG, Colhoun K, Newton SF, Houghton JDR, Reid N (2012) Foraging trip time-activity budgets and reproductive success in the black-legged kittiwake. Mar Ecol Prog Ser 456:269-277

Chivers LS, Hatch SA, Elliott KH (2016) Accelerometry reveals an impact of short-term tagging on seabird activity budgets. Condor 118:159-168

Christensen RHB (2019) Package 'ordinal'. https://cran.rproject.org/web/packages/ordinal/ordinal.pdf

* Christensen-Dalsgaard S, May R, Lorentsen S (2018) Taking a trip to the shelf: behavioral decisions are mediated by the proximity to foraging habitats in the black-legged kittiwake. Ecol Evol 8:866-878

Courbin N, Besnard A, Péron C, Saraux C and others (2018) Short-term prey field lability constrains individual specialisation in resource selection and foraging site fidelity in a marine predator. Ecol Lett 21:1043-1054

Daunt F, Benvenuti S, Harris MP, Dall'Antonia L, Elston DA, Wanless S (2002) Foraging strategies of the black-legged kittiwake Rissa tridactyla at a North Sea colony: evidence for a maximum foraging range. Mar Ecol Prog Ser 245:239-247

* Dean B, Freeman R, Kirk H, Leonard K, Phillips RA, Perrins CM, Guilford T (2013) Behavioural mapping of a pelagic seabird: combining multiple sensors and hidden Markov models reveals at-sea behaviour and key foraging areas. J R Soc Interface 10:20120570

* Di Lorenzo E, Mantua N (2016) Multi-year persistence of the 2014/15 North Pacific marine heatwave. Nat Clim Change 6:1042-1047 
Elliott KH, Chivers LS, Bessey L, Gaston AJ and others (2014) Windscapes shape seabird instantaneous energy costs but adult behavior buffers impact on offspring. Mov Ecol 2:17

Fleming CH, Fagan WF, Mueller T, Olson KA, Leimgruber P, Calabrese JM (2015) Rigorous home range estimation with movement data: a new autocorrelated kernel density estimator. Ecology 96:1182-1188

Freeland H, Whitney F (2014) Unusual warming in the Gulf of Alaska. PICES Press 22:51-52

Frölicher TL, Fischer EM, Gruber N (2018) Marine heatwaves under global warming. Nature 560:360-364

Gibble C, Duerr R, Bodenstein B, Lindquist K and others (2018) Investigation of a largescale common murre (Uria aalge) mortality event in California, USA, in 2015. J Wildl Dis 54:569-574

* Gutowsky SE, Gutowsky LFG, Jonsen ID, Leonard ML, Naughton MB, Romano MD, Shaffer SA (2014) Daily activity budgets reveal a quasi-flightless stage during non-breeding in Hawaiian albatrosses. Mov Ecol 2:23

Hamer KC, Monaghan P, Uttley JD, Walton P, Burns MD (1993) The influence of food supply on the breeding ecology of kittiwakes Rissa tridactyla in Shetland. Ibis 135: 255-263

Harvell CD, Montecino-Latorre D, Caldwell JM, Burt JM and others (2019) Disease epidemic and a marine heatwave are associated with the continental-scale collapse of a pivotal predator (Pycnopodia helianthoides). Sci Adv 5:eaau7042

Harwood LA, Quakenbush LT, Small RJ, George JC and others (2017) Movements and inferred foraging by bowhead whales in the Canadian Beaufort sea during August and September, 2006-12. Arctic 70:161-176

Hatch SA (2013) Kittiwake diets and chick production signal a 2008 regime shift in the Northeast Pacific. Mar Ecol Prog Ser 477:271-284

Holbrook NJ, Scannell HA, Sen Gupta A, Benthuysen JA and others (2019) A global assessment of marine heatwaves and their drivers. Nat Commun 10:2624

Hothorn T (2020) R package 'multcomp'. https://cran.rproject.org/web/packages/multcomp/multcomp.pdf

Institute for Seabird Research and Conservation (2018) Middleton Island seabird research and monitoring: 2018 Field Report. Institute for Seabird Research and Conservation, Anchorage, AK

Jones T, Parrish JK, Peterson WT, Bjorkstedt EP and others (2018) Massive mortality of a planktivorous seabird in response to a marine heatwave. Geophys Res Lett 45: 3193-3202

Jones T, Divine LM, Renner H, Knowles S and others (2019) Unusual mortality of tufted puffins (Fratercula cirrhata) in the eastern Bering Sea. PLOS ONE 14:e0216532

Kessler AE, Batbayar N, Natsagdorj T, Batsuur' D, Smith AT (2013) Satellite telemetry reveals long-distance migration in the Asian great bustard Otis tarda dybowskii. J Avian Biol 44:311-320

Kirkpatrick L, Graham J, McGregor S, Munro L, Scoarize M, Park K (2018) Flexible foraging strategies in Pipistrellus pygmaeus in response to abundant but ephemeral prey. PLOS ONE 13:e0204511

Kroeger C, Crocker DE, Thompson DR, Torres LG, Sagar P, Shaffer SA (2019) Variation in corticosterone levels in two species of breeding albatrosses with divergent life histories: responses to body condition and drivers of foraging behavior. Physiol Biochem Zool 92:223-238
Kangton SD, Collett D, Sibly RM (1995) Splitting behaviour into bouts; a maximum likelihood approach. Behaviour 132:781-799

Luque SP (2020) R package 'diveMove'. https://cran.rproject.org/web/packages/diveMove/diveMove.pdf

Luque SP, Arnould JPY, Guinet C (2008) Temporal structure of diving behaviour in sympatric Antarctic and subantarctic fur seals. Mar Ecol Prog Ser 372:277-287

Mantua NJ, Hare SR (2002) The Pacific Decadal Oscillation. J Oceanogr 58:35-44

Mantua NJ, Hare SR, Zhang Y, Wallace JM, Francis RC (1997) Pacific interdecadal climate oscillation with impacts on salmon production. Bull Am Meteorol Soc 78: 1069-1079

Masello JF, Mundry R, Poisbleau M, Demongin L, Voigt CC, Wikelski M, Quillfeldt P (2010) Diving seabirds share foraging space and time within and among species. Ecosphere 1:art19

McCabe RM, Hickey BM, Kudela RM, Lefebvre KA and others (2016) An unprecedented coastwide toxic algal bloom linked to anomalous ocean conditions. Geophys Res Lett 43:10366-10376

* Miner CM, Burnaford JL, Ambrose RF, Antrim L and others (2018) Large-scale impacts of sea star wasting disease (SSWD) on intertidal sea stars and implications for recovery. PLOS ONE 13:e0192870

*Montevecchi WA, Hedd A, McFarlane Tranquilla L, Fifield DA and others (2012) Tracking seabirds to identify ecologically important and high risk marine areas in the western North Atlantic. Biol Conserv 156:62-71

NOAA (2020) 2015-2020 Guadalupe fur seal unusual mortality event in California, Oregon and Washington. https:// www.fisheries.noaa.gov/national/marine-life-distress/ 2015-2020-guadalupe-fur-seal-unusual-mortality-eventcalifornia

Norberg RA (1981) Optimal flight speed in birds when feeding young. J Anim Ecol 50:473-477

* Oliver ECJ, Burrows MT, Donat MG, Sen Gupta A and others (2019) Projected marine heatwaves in the 21st century and the potential for ecological impact. Front Mar Sci 6:734

Osborne OE (2018) Foraging trip trends and delineation of foraging areas of black-legged kittiwakes (Rissa tridactyla) during the breeding season, on Middleton Island, Alaska. Master of GIS Applications thesis, Vancouver Island University, Nanaimo

* Paredes R, Orben RA, Suryan RM, Irons DB and others (2014) Foraging responses of black-legged kittiwakes to prolonged food-shortages around colonies on the Bering Sea shelf. PLOS ONE 9:e92520

Peterson W, Robert M, Bond N (2015) The warm blob - conditions in the northeastern Pacific Ocean. PICES Press 23:36-38

* Piatt JF, Parrish JK, Renner HM, Schoen SK and others (2020) Extreme mortality and reproductive failure of common murres resulting from the northeast Pacific marine heatwave of 2014-2016. PLOS ONE 15:e022 6087

* Pinaud D, Weimerskirch H (2007) At-sea distribution and scale-dependent foraging behaviour of petrels and albatrosses: a comparative study. J Anim Ecol 76:9-19

Follet IL, Ronconi RA, Jonsen ID, Leonard ML, Taylor PD, Shutler D (2014) Foraging movements of Leach's stormpetrels Oceanodroma leucorhoa during incubation. J Avian Biol 45:305-314 
Rekdahl ML, Dunlop RA, Goldizen AW, Garland EC, Biassoni N, Miller P, Noad MJ (2015) Non-song social call bouts of migrating humpback whales. J Acoust Soc Am 137:3042-3053

Roberts JJ, Best BD, Dunn DC, Treml EA, Halpin PN (2010) Marine Geospatial Ecology Tools: an integrated framework for ecological geoprocessing with ArcGIS, Python, R, MATLAB, and C++. Environ Model Softw 25:1197-1207

Sanford E, Sones JL, García-Reyes M, Goddard JHR, Largier JL (2019) Widespread shifts in the coastal biota of northern California during the 2014-2016 marine heatwaves. Sci Rep 9:4216

Savage K (2017) Alaska and British Columbia large whale unusual mortality event summary report. NOAA Fisheries. https://repository.library.noaa.gov/view/noaa/17715

Sibly RM, Nott HMR, Fletcher DJ (1990) Splitting behaviour into bouts. Anim Behav 39:63-69

Soanes LM, Arnould JPY, Dodd SG, Sumner MD, Green JA (2013) How many seabirds do we need to track to define home-range area? J Appl Ecol 50:671-679

Sullivan FA, Torres LG (2018) Assessment of vessel disturbance to gray whales to inform sustainable ecotourism. J Wildl Manag 82:896-905

Suryan RM, Irons DB, Benson J (2000) Prey switching and variable foraging strategies of black-legged kittiwakes and the effect on reproductive success. Condor 102:374-384

* Torres LG, Orben RA, Tolkova I, Thompson DR (2017) Classification of animal movement behavior through residence in space and time. PLoS ONE 12:e0168513

Von Biela VR, Arimitsu ML, Piatt JF, Heflin B, Schoen SK, Trowbridge JL, Clawson CM (2019) Extreme reduction in nutritional value of a key forage fish during the Pacific marine heatwave of 2014-2016. Mar Ecol Prog Ser 613: 171-182

Editorial responsibility: Robert Suryan, Juneau, Alaska, USA
Votier SC, Fayet AL, Bearhop S, Bodey TW and others (2017) Effects of age and reproductive status on individual foraging site fidelity in a long-lived marine predator. Proc R Soc B 284:20171068

*Walsh JE, Thoman RL, Bhatt US, Bieniek PA and others (2018) The high latitude marine heatwave of 2016 and its impacts on Alaska. Bull Am Meteorol Soc 99:S39-S43

*Weimerskirch H (1998) How can a pelagic seabird provision its chick when relying on a distant food resource? Cyclic attendance at the colony, foraging decision and body condition in sooty shearwaters. J Anim Ecol 67: 99-109

Whitney FA (2015) Anomalous winter winds decrease 2014 transition zone productivity in the NE Pacific. Geophys Res Lett 42:428-431

* Yang S, Yuan M, Yang Q, Huang J and others (2019) Coccolithophore responses to the Pacific Decadal Oscillation in the East China Sea region of the Northwest Pacific from AD 1901 to 2013. J Quaternary Sci 34:333-341

* Ydenberg RC, Davies WE (2010) Resource geometry and provisioning routines. Behav Ecol 21:1170-1178

* Yorio P, Quintana F, Dell'arciprete P, González-Zevallos D (2010) Spatial overlap between foraging seabirds and trawl fisheries: implications for the effectiveness of a marine protected area at Golfo San Jorge, Argentina. Bird Conserv Int 20:320-334

Zador S, Yasumiishi E (eds) (2018) Ecosystem status report 2018 Gulf of Alaska. Western Gulf of Alaska 2018 Report Card. North Pacific Fishery Management Council, Anchorage, AK. https://access.afsc.noaa.gov/REFM/ REEM/ecoweb/pdf/2018ecosysGOA-508.pdf

Zambom AZ, Dias R (2013) A review of kernel density estimation with applications to econometrics. Int Econometric Rev 5:20-42

Submitted: February 18, 2020; Accepted: June 15, 2020

Proofs received from author(s): July 27, 2020 